\title{
ATRIBUTOS MICROBIOLÓGICOS E BIOQUÍMICOS COMO INDICADORES DA RECUPERAÇÃO DE ÁREAS DEGRADADAS, NO SUL DE MINAS GERAIS
}

\section{Microbial and Biochemical Parameters as Indicators of Soil Rehabilitation in the South of Minas Gerais State}

\author{
Rafael Botelho Silveira ${ }^{1}$ \\ Rogério Melloni ${ }^{2}$ \\ Eliane Guimarães Pereira ${ }^{2}$
}

\section{Resumo}

O objetivo deste trabalho foi avaliar e comparar atributos microbiológicos e bioquímicos de solos de áreas degradadas, em recuperação, com outras consideradas naturais, sem interferência antrópica recente, em Itajubá (MG), para verificar aí sua capacidade de indicar a qualidade do solo. Para isso, amostras de solo foram coletadas em fevereiro de 2003 (verão) em seis áreas, sendo três em naturais e três em degradadas (em recuperação). Foram avaliados a densidade de fungos e bactérias, microorganismos solubilizadores de fosfato, biomassa $\mathrm{C}$ e atividades microbianas. Paralelamente, foram estabelecidas relações entre atributos visuais de qualidade do solo com aqueles microbiológicos e bioquímicos, verificando sua capacidade de utilização como indicadores da recuperação destes solos em áreas degradadas. A degradação das áreas promoveu forte impacto negativo na microbiota do solo, reduzindo o número de todos os grupos de microorganismos estudados, atividade e biomassa microbianas. Os microorganismos foram considerados bons indicadores da recuperação de solos das áreas degradadas. A recuperação observada sobre o solo por meio de atributos visuais não apresentou relação com aquela observada por atributos microbiológicos e bioquímicos. Os resultados comprovam que a recuperação das áreas degradadas está fortemente limitada por parâmetros microbiológicos e bioquímicos do solo.

Palavras-chave: Solo degradado, Microorganismos do solo, Atividade microbiana, Biomassa microbiana.

\section{Abstract}

This paper intends to evaluate and to compare the microbial and biochemical parameters of degraded areas, in rehabilitation, with other natural one, considered reference without recent human interference, in Itajuba (MG, Brazil), to verify their capacity to indicate the soil quality and rehabilitation. Soil samples were collected in February 2003 (summer), on six sites, being three on natural areas and three on degraded areas, under rehabilitation. It was evaluated total density of fungi and bacteria, phosphate solubilized by microorganisms, microbial biomass $\mathrm{C}$ and activity. Besides, it will be established relationships among visual parameters with those microbial and biochemical ones, verifying their using as potential indicators in studies of soil rehabilitation on degraded areas. Degradation promoted strong negative impact in the soil microbiota, reducing the number of all microbial groups studied, microbial activity and biomass. The soil microbial and biochemical parameters were considered good indicators of the soil rehabilitation on those degraded areas. The rehabilitation evidenced above the soil by the visual parameters of soil, plants and organisms had not direct positive relationship with those observed in the underground through microbial and biochemical indicators. These findings prove that rehabilitation of degraded areas is strongly limited for soil microbial and biochemical parameters.

Keywords: Degraded soil, Soil microorganisms, Microbial activity, Microbial biomass.

1 Discente do Curso de Engenharia Ambiental, da Universidade Federal de Itajubá (UNIFEI). Bolsista CNPq. Email: rafabsilveira@yahoo.com.br.

2 Engenheiro Agrônomo, Prof. Dr. Adjunto do Instituto de Recursos Naturais da UNIFEI. Av. BPS, 1303 - Pinheirinho, Itajubá/MG. CEP 37500-900. E-mail: rmelloni@unifei.edu.br e egpereira@unifei.edu.br. 


\section{Introdução}

Até recentemente, a maioria dos estudos de qualidade do solo era relacionada à utilização de indicadores físicos e químicos (DORAN et al., 1994). No entanto, muitos dos atributos físicos e químicos do solo, exigidos para o máximo desenvolvimento vegetal, são afetados diretamente pelos processos bióticos, destacando-se a importância dos microorganismos e seus processos no funcionamento e equilíbrio de ecossistemas (LEE, 1994). Entre os atributos microbiológicos e bioquímicos que apresentam grande potencial de utilização como indicadores sensíveis do estresse ecológico destacam-se a densidade total de bactérias, fungos, solubilizadores de fosfato, biomassa microbiana e atividade de microorganismos heterotróficos.

Os microorganismos estão diretamente envolvidos nos ciclos dos nutrientes no solo e, aliada à quantificação de bactérias e fungos totais, a avaliação de determinados grupos microbianos dá indicação de como os processos bioquímicos estão ocorrendo. Segundo Brookes (1995), a contagem de microorganismos no solo, apesar de ser vista com ressalvas, ajuda a entender os processos que nele ocorrem e pode servir como indicador do impacto de diferentes atividades antrópicas.

A biomassa microbiana do solo é definida como a parte viva da matéria orgânica e, além de armazenadora de nutrientes, pode servir como um indicador rápido de mudanças no solo, revelando a sensibilidade da microbiota a interferências no sistema (GRISI, 1995). Sua avaliação dá indicações sobre a ciclagem da matéria orgânica, podendo atuar como fonte e dreno de nutrientes por meio de processos de mineralização e imobilização. A vegetação influencia diferentemente a biomassa microbiana e, por isto, a sua eliminação ocasiona uma drástica queda da biomassa carbono, como revelam estudos envolvendo desmatamentos (CERRI et al., 1985; CAMPOS, 1998). Como a avaliação da biomassa microbiana é relativamente rápida quando comparada à avaliação direta da produtividade vegetal, esta pode ter enorme aplicação na avaliação da qualidade de solo. Nem sempre há correlações entre biomassa e atividade microbianas e entre biomassa e a comunidade microbiana em estudo. No entanto, resultados obtidos por Cattelan e Vidor (1990) em solos degradados, e por Kuperman e Carreiro (1997) e Dias-
Júnior et al. (1998) em solos contaminados com metais pesados mostraram haver correlações significativas entre biomassa e atividade microbianas e entre biomassa e populações de fungos e bactérias cultiváveis.

A degradação da matéria orgânica é uma propriedade de todos os microorganismos heterotróficos e seu nível é comumente utilizado para indicar a atividade microbiana do solo. Segundo Nannipieri (1984), a atividade microbiana é utilizada como uma maneira de melhor entender os processos de mineralização e visualizar mais profundamente a intensidade dos fluxos de energia no solo. A respiração microbiana apresenta grande potencial de utilização como indicador da qualidade de solos em áreas degradadas, relacionando-se com a perda de carbono orgânico do sistema solo-planta para a atmosfera, reciclagem de nutrientes, resposta a diferentes estratégias de manejo do solo (PARKIN et al., 1996).

Por meio de atributos microbiológicos e bioquímicos, Melloni et al. (2000) e Melloni et al. (2001a) avaliaram o impacto de diferentes doses de resíduo de siderurgia na microbiota do solo sob eucalipto e soja, respectivamente, e verificaram que esses foram fundamentais na seleção de doses não impactantes. Ainda, Melloni et al. (2001b), em estudos envolvendo ecossistemas de campo e mata, no sul de Minas Gerais, verificaram que, com a utilização destes atributos, foi possível discriminar os diferentes ecossistemas e registrar a presença de uma comunidade microbiana mais ativa nos solos de mata. Estes resultados, aliados a de outros pesquisadores, evidenciam a grande flexibilidade de utilização e a sensibilidade destes atributos em indicar alterações na comunidade microbiana do solo decorrentes de atividades antrópicas diversas (KUPERMAN; CARREIRO, 1997; CARNEIRO, 2000; VARGAS; SCHOLES, 2000).

Devido à alta sensibilidade relacionada à atividade antrópica e à simplicidade de determinação, atributos microbiológicos (densidade e diversidade de grupos funcionais de microorganismos) e bioquímicos (biomassa microbiana e atividade de microorganismos heterotróficos) apresentam grande potencial de utilização como indicadores da qualidade de solos degradados em recuperação (GRISI, 1995; NANNIPIERI, 1984; GIANFREDA e BOLAG, 1996). Pela avaliação desses atributos, inclusive em área-referência ou natural sem impacto de atividades antrópicas, podem ser 
identificadas as principais limitações do ecossistema impactado e sugeridas estratégias visando a manter a sustentabilidade de ecossistemas. Assim, os objetivos foram avaliar atributos microbiológicos e bioquímicos de solos de áreas degradadas em revegetação e de áreas-referência, e verificar a adequabilidade de sua utilização como indicadores da qualidade desses solos, comparando-se com a avaliação in situ de características relacionadas ao solo, vegetação e fauna do solo.

\section{Material e métodos}

Dois ecossistemas (identificados como N - natural e R - em recuperação) foram estudados em área localizada em Itajubá, sul de Minas Gerais. $\mathrm{O}$ ecossistema $\mathrm{N}$ é uma área-modelo de cerca de 0,02ha, que foi dividida em 3 subáreas (N1, N2 e N3), com alta declividade, sem interferência antrópica recente, coberta totalmente com capimgordura e arbustos de espécies diversas. A área N1 foi considerada como referência por apresentar melhores aspectos visuais de solo e vegetação. $\mathrm{O}$ ecossistema $\mathrm{R}$ foi dividido em 3 subáreas (R1, R2 e R3) com alta declividade, revegetada há dois anos (R1 e R2) ou menos (R3) com várias espécies rasteiras e arbustivas, incluindo feijão-guandu, feijãode-porco, mucuna-cinza e espécies arbóreas como araucária, paineira, jacarandá, guapuruvu, entre outras nativas.

\section{Amostragens de solo e análises microbiológicas}

Para a amostragem, realizada em janeiro de 2003, as áreas foram demarcadas em transectos de 4 x $25 \mathrm{~m}$, e a coleta das subamostras de solo foi realizada em ziguezague, num total de 4 amostras compostas por área, formadas por 10 subamostras cada, na profundidade de $0-10 \mathrm{~cm}$. As amostras de solo foram acondicionadas em sacos plásticos e encaminhadas ao Laboratório de Microbiologia, da UNIFEI, para a avaliação dos atributos microbiológicos e bioquímicos.

O número mais provável (NMP) de bactérias e fungos do solo foi determinado pelo método do plaqueamento por gotas, após diluição de amostras de solo em meios de cultura mantidos a $45^{\circ} \mathrm{C}$, conforme Jahnel et al. (1999). O número total de microorganismos solubilizadores de fosfato presentes nos solos foi determinado por meio de unidades formadoras de colônias (UFC), utilizando-se o método de inoculação de suspensões diluídas de solo em meios de cultura específicos, com 3 repetições por diluição. Os meios utilizados foram: ágar nutriente para bactérias totais, meio Martin para fungos totais, conforme Wollum II (1982) e meio GES para microorganismos solubilizadores de fosfato (SILVESTER-BRADLEY et al., 1982). As placas com os meios inoculados foram incubadas em temperatura de $27^{\circ} \mathrm{C}$ e avaliadas aos três dias para bactérias e aos sete dias para fungos e microorganismos solubilizadores de fosfato.

\section{Análises bioquímicas do solo}

O carbono da biomassa e a atividade microbiana foram avaliados, segundo Ferreira et al. (1999), empregando-se o método da irradiação/incubação, o qual apresenta como princípio básico a eliminação de microorganismos pela irradiação eletromagnética de forno de microondas, antes da avaliação da quantidade de $\mathrm{CO}_{2}$ liberada após incubação por 10 dias, à temperatura ambiente.

\section{Avaliação in situ da recuperação do solo}

Utilizou-se uma planilha desenvolvida no Laboratório de Microbiologia do Solo da Universidade Federal de Lavras (UFLA) para avaliação de características de solo, vegetação e fauna, objetivando cálculo de um índice de qualidade do solo, baseado em Melloni (2001c). As notas variaram de 0 (pior) a 5 (melhor ou referência), em um total de 58 pontos, e foram calibradas com a área naturalN1 (sem interferência antrópica), sendo para esta atribuídos os maiores valores.

Os valores foram ponderados em função da importância atribuída à reabilitação e à condição da referência, sendo de 100, 50 e 50\% da nota atribuída para erosão, pedregosidade e fauna do solo, respectivamente; de 100, 80, 50, 100, 100, 100, 70 e 100\% para índice de cobertura, índice de diversidade, porte/ estratificação, vigor da vegetação, quantidade de serapilheira, estado de decomposição da serapilheira, incorporação da serapilheira e sucessão na vegetação, respectivamente; e de $50 \%$ para a presença de fauna silvestre. 
Análise dos resultados

De posse dos resultados dos atributos microbiológicos, bioquímicos ou aqueles obtidos in situ, as áreas foram agrupadas em dendrogramas de similaridade, utilizando-se o método Complete Linkage e Distância Euclidiana (Everitt, 1993), pelo programa STATISTICA 5.0. Com as médias dos valores dos atributos microbiológicos (número total de fungos, bactérias, solubilizadores de fosfato), bioquímicos (atividade e $\mathrm{C}$ da biomassa microbiana) e químicos ( $\mathrm{pH}$ ) obtidos das amostras de solo das diferentes áreas, procedeu-se à análise de componentes principais (PCA), utilizando-se o programa PC-ORD 3.12 (MCCUNE; MEFFORD, 1997).

\section{Resultados e discussão}

Os resultados obtidos para todos os atributos estudados estão na tabela 1 .

\section{Tabela 1 - Atributos microbiológicos, bioquímicos, nota da avaliação in situ e pH das amostras de solo das áreas de estudo.}

Table 1 - Microbiological and biochemical attributes, in situ evaluation index and $\mathrm{pH}$ of the soil samples of the study areas.

\begin{tabular}{|c|c|c|c|c|c|c|c|}
\hline \multirow[t]{2}{*}{ Áreas } & \multirow{2}{*}{$\begin{array}{l}\text { Nota da } \\
\text { avaliação } \\
\text { in situ das } \\
\text { áreas }\end{array}$} & Fungos & Bactérias & $\begin{array}{l}\text { Solubilizadores } \\
\text { de fosfato }\end{array}$ & $\begin{array}{l}\text { Atividade } \\
\text { microbiana }\end{array}$ & $\begin{array}{l}\text { C da } \\
\text { biomassa }\end{array}$ & $\begin{array}{l}\text { pH de amostras } \\
\text { de solo }\end{array}$ \\
\hline & & \multicolumn{2}{|c|}{$\begin{array}{l}\log \text { NMP } g^{-1} \text { de solo } \\
\text { seco }\end{array}$} & $\begin{array}{l}\log \mathrm{UFC}^{-1} \mathrm{de} \\
\text { solo seco }\end{array}$ & $\begin{array}{l}\mathrm{mgCO}_{2} \\
100 \mathrm{~g}^{-1} \mathrm{de} \\
\text { solo seco }\end{array}$ & $\begin{array}{l}\mu g g^{-1} \text { de } \\
\text { de solo } \\
\text { seco }\end{array}$ & $\begin{array}{l}1: 2,5 \\
\mathrm{CaCl}_{2}\end{array}$ \\
\hline N1 & 32,90 & 5,61 & 6,48 & 4,70 & 18,48 & 141,39 & 4,51 \\
\hline N2 & 28,93 & 5,42 & 6,66 & 4,39 & 22,10 & 93,05 & 4,53 \\
\hline N3 & 25,55 & 5,53 & 6,75 & 4,19 & 18,16 & 117,22 & 4,43 \\
\hline $\mathrm{R} 1$ & 23,13 & 5,12 & 6,00 & 4,33 & 17,46 & 22,27 & 4,45 \\
\hline $\mathrm{R} 2$ & 17,60 & 5,32 & 6,42 & 3,75 & 14,10 & 22,84 & 4,32 \\
\hline R3 & 10,08 & 5,02 & 6,03 & 3,34 & 6,47 & 22,81 & 4,71 \\
\hline
\end{tabular}

Análise in situ da recuperação do solo

Verificou-se que todas as áreas consideradas naturais, sem interferência antrópica recente, apresentaram valores superiores àqueles das áreas em recuperação, principalmente as áreas R2 e R3, as quais apresentaram déficit de 47 e $69 \%$ em relação ao maior valor obtido na área N1 (referência), considerado 100\%. Estas últimas áreas apresentaram problemas evidentes de erodibilidade, ausência de fauna do solo, menor índice de cobertura vegetal, ausência de estratificação vegetal e domínio de vegetação rasteira, menor quantidade de serapilheira e fauna silvestre. No entanto, a área R1 apresentou déficit de apenas $30 \% \mathrm{em}$ relação à N1, em virtude do baixo índice de cobertura vegetal, predisposição a processos erosi- vos e baixa quantidade, decomposição e incorporação de serapilheira.

Assim, verificou-se que o índice de recuperação estimado por atributos de solo, vegetação e macroorganismos do solo e silvestres observados in situ, possibilita o acompanhamento da recuperação de áreas degradadas, servindo de suporte para alteração e ou intensificação de estratégias adotadas com este propósito.

Agrupamento das áreas por atributos de solo, vegetação e macroorganismos avaliados in situ

O agrupamento das áreas com base nos atributos observados in situ está apresentado na figura 1a. As áreas N1 e N2 apresentaram 80\% de 
similaridade, igual às áreas N3 e R1. Já as áreas R2 e R3 apresentaram $65 \%$ de similaridade, sem nenhuma similaridade às anteriores. Este tipo de agrupamento auxiliou nos estudos de interpretação dos resultados visuais e foi suficiente para mostrar a maior similaridade da área R1 com as naturais, a superioridade das áreas N1 e N2 com relação aos atributos de solo, vegetação e macroorganismos do solo e silvestre avaliados in situ, e a grande distância de recuperação das áreas R2 e R3 com as demais, já evidenciada pelas notas atribuídas in situ.

\section{Figura 1 - Dendrogramas de similaridade construídos de acordo com: a) notas obtidas dos} atributos avaliados in situ nas áreas de estudo; b) atributos microbiológicos (número total de fungos, bactérias, solubilizadores de fosfato) e bioquímicos (atividade e biomassa microbianas) de amostras de solo das áreas de estudo.

Figure 1 -Similarity dendrograms constructed by: a) index obtained from attribute evaluated in situ of the study areas b) microbiological (fungi and bacteria that make phosphate soluble) and biochemical (microbian biomass activity) attributes of soil samples from study areas.

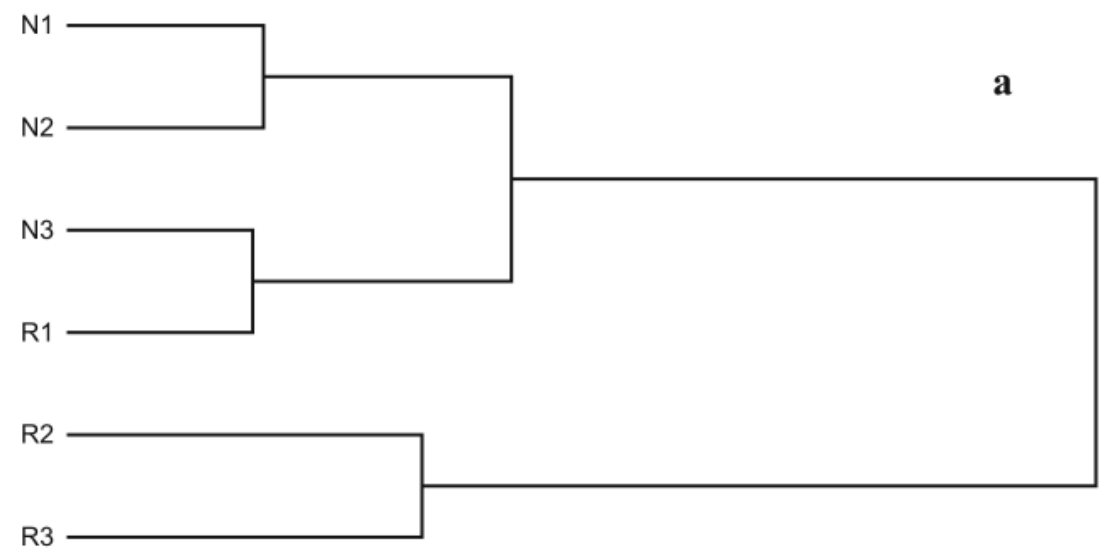

$\begin{array}{lllllll} & 00 & 60 & 40 & 20 & 0 & 110\end{array}$
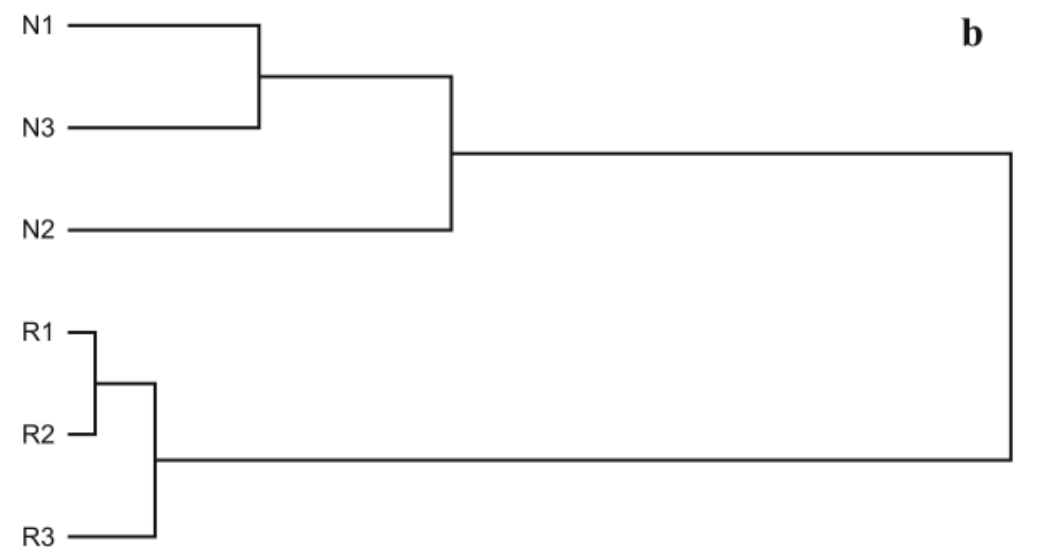

$\begin{array}{rrrrrr}100 & 80 & 60 & 40 & 20 & 0\end{array}$




\section{Figura 2 - Análise de componentes principais para os atributos microbiológicos (SOL P- solubilizadores de fosfato, NFUNGOS, NBACTERIAS) e bioquímicos (ATIVIDADE, C BIOMASSA) e notas (NOTA in situ) obtidas in situ nas áreas de estudo.}

Figure 2 - Principal component analysis for microbiological (SOL P- microorganisms that make phosphate soluble, NFUNGOSfungi, NBACTERIASbacteria) and biochemical (ATIVIDADE-activity, C BIOMASSA-carbon biomass) attributes, and index (NOTA in situ) evaluated in situ in the study areas.

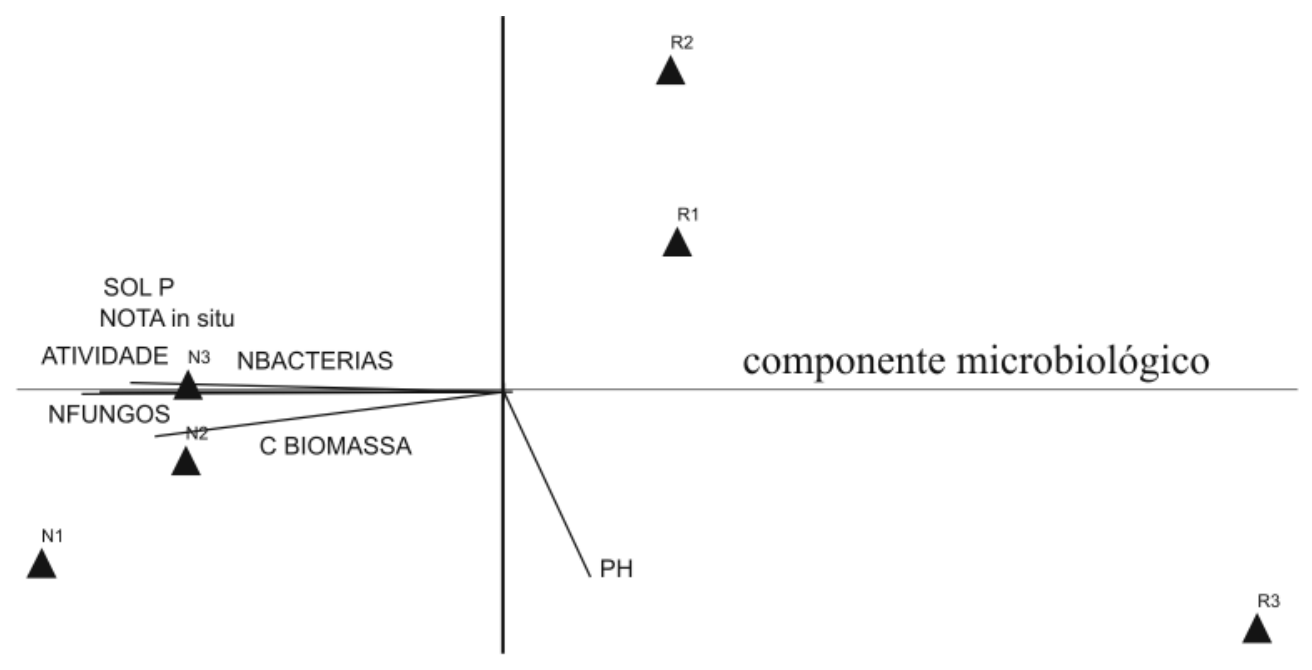

Agrupamento das áreas por atributos microbiológioos e bioquímioos

O dendrograma de similaridade das áreas de estudo, construído com base nos atributos microbiológicos e bioquímicos está apresentado na figura $1 \mathrm{~b}$. Dois grandes grupos foram formados a $60 \%$ de similaridade, sendo um com as áreas consideradas naturais e outro com as áreas em recuperação. As áreas N1 e N3 apresentaram 80\% de similaridade entre si e $60 \%$ com relação a N2, enquanto as áreas R1, R2 e R3 apresentaram 90\% de similaridade entre si e sem agrupamento com as naturais. Pelos atributos microbiológicos e bioquímicos do solo, diferentemente do observado com o agrupamento pelos atributos in situ (agrupamento da área N3 com R1), a área R1 se agrupou com as demais áreas em recuperação, mostrando que essas estão em processo de recuperação, mas ainda distantes daquelas consideradas naturais, principalmente com relação à microbiota do solo. Esse resultado concorda com o observado por Melloni (2001c) e também evidencia que nem sempre o que ocorre sobre o solo (comprovado por aspectos visuais) tem relação com o que ocorre abaixo dele, notadamente com relação a aspectos microbiológicos e bioquímicos. Portanto, a avaliação da recuperação por meio da porcentagem de cobertura vegetal, diversidade florística e fauna silvestre, como proposta por Brower e Zar (1977), não reflete a condição microbiológica e a funcionalidade dos solos em recuperação e evidenciam a grande discrepância existente entre os atributos microbiológicos e bioquímicos das áreas em recuperação com as consideradas naturais.

Análise de componentes principais

Da análise de componentes principais (PCA), três componentes principais (PC) foram extraídos dos atributos microbiológicos, bioquímicos, nota atribuída in situ e pH do solo (tabela 2), sendo a análise destes representada graficamente na figura 2 . 


\section{Tabela 2 - Valores dos autovetores obtidos na análise de componentes para os atributos nas} áreas de estudo.

Table 2 - Autovectors obtained from principal component analysis for attributes of study áreas.

\begin{tabular}{llll}
\hline Variáveis & PC1 & PC2 & PC3 \\
\hline N fungos & $\underline{-0,4201}$ & $-0,0590$ & $+0,3276$ \\
N bactérias & $\underline{-0,3603}$ & $+0,0154$ & $\underline{+0,6217}$ \\
Atividade & $\underline{-0,4033}$ & $+0,1826$ & $-0,3013$ \\
C biomassa & $\underline{-0,3895}$ & $-0,4351$ & $+0,1945$ \\
Solubilizadores de P & $\underline{-0,3968}$ & $-0,0410$ & $-0,5187$ \\
Nota in situ & $\underline{-0,4294}$ & $-0,0881$ & $-0,3083$ \\
pH do solo & $+0,1935$ & $-0,8742$ & $-0,1155$ \\
\hline
\end{tabular}

Valores sublinhados indicam aqueles que foram utilizados na interpretação dos componentes principais $(>|0,36|)$.

Os três PCs compuseram 96,6\% da variância total dos dados, sendo que o PC1 apresentou $70,9 \%$ da variância total e denominado "componente microbiológico" pelo fato de a maioria dos atributos microbiológicos e bioquímicos estudados apresentar correlação superior ao estabelecido para interpretação (| 0,36| ). O PC2 compôs $14,6 \%$ da variância total, enquanto o PC3 participou com 11,1\% da variância total, não sendo, por isso, demonstrado na figura 2.

Verificou-se que as áreas em recuperação $(\mathrm{R})$ o cuparam posições opostas àquelas consideradas naturais $(\mathrm{N})$ no mesmo componente microbiológico, mostrando a distância evidente entre elas quanto aos aspectos microbiológicos e bioquímicos. Com esta distribuição, as áreas $\mathrm{N}$ apresentaram maior proximidade entre si, concordando com o agrupamento pelos atributos microbiológicos e bioquímicos (figura 1b) e, portanto, com comunidade microbiana maior e mais ativa, possivelmente devido a maior cobertura vegetal e maior adição de matéria orgânica ao solo. Inversamente, a recuperação das áreas $R$, com destaque para R3, está sendo negativamente afetada pela ausência destes atributos.

\section{Conclusões}

Atividades antrópicas exercidas nas áreas de estudo provocaram forte impacto negativo na microbiota do solo, reduzindo o número de bactérias, fungos, solubilizadores de fosfato, atividade e biomassa microbianas.

Os atributos microbiológicos e bioquímicos do solo estudados podem ser considerados bons indicadores da recuperação de áreas degradadas.

Os atributos microbiológicos/bioquímicos e atributos avaliados in situ das áreas produziram agrupamentos diferentes, mostrando que não há relação entre a recuperação, aparentemente observada sobre o solo, com a microbiota e sua atividade.

A análise de componentes principais comprova que a recuperação das áreas impactadas está fortemente limitada por atributos microbiológicos e bioquímicos do solo. 


\section{Referências}

BROOKES, P.C. The use of microbial parameters in monitoring soil pollution by heavy metals. Biology and Fertility of Soils, Berlin, v. 19, p. 269-279, 1995.

BROWER, J.E.; ZAR, J.H. Field \& laboratory methods for general ecology. Dubuque: Iowa Wm. C. Brown, 1977. p. 8-20.

CARNEIRO, M.A.C. Características bioquímicas do solo em duas cronosseqüências de reabilitação em áreas de mineração de bauxita. Lavras, 2000. 166f. Tese (Doutorado em Solos e Nutrição de Plantas) - Lavras, UFLA, 2000

CATTELAN, A.J.; VIDOR, C. Sistemas de culturas e a população microbiana do solo. Revista Brasileira de Ciência do Solo, Campinas, v. 14, n. 2, p. 125-132, 1990.

CERRI, C.C.; VOLKOFF, B.; EDUARDO, B.P. Efeito do desmatamento sobre a biomassa microbiana em Latossolo Amarelo da Amazônia. Revista Brasileira de Ciência do Solo, Campinas, v. 9, n. 1, p. 1-4, jan./abr. 1985.

DIAS-JÚNIOR, H.E. et al. Metais pesados, densidade e atividade microbiana em solo contaminado por rejeitos de indústria de zinco. Revista Brasileira de Ciência do Solo, Viçosa, v. 22, n. 4, p. 631-640, 1998.

DORAN, J.W. et al. (Eds.) Defining soil quality for a sustainable environment. Wisconsin: American Society of Agronomy, 1994.

EVERITT, B.S. Cluster analysis. New York: J. Wiley, p. 170, 1993.

FERREIRA, A.S.; CAMARGO, F.A.O.; VIDOR, C. Utilização de microondas na avaliação da biomassa microbiana do solo. Revista Brasileira de Ciência do Solo, Viçosa, v. 23, n. 4, p. 991996, 1999.

GIANFREDA, L.; BOLAG, J.M. Influence of natu$\mathrm{ral}$ and anthropogenic factors on enzyme activity in soil. In: STOTZKY, G. e BOLAG, J.M. (eds). Soil Biochemistry, New York, v. 9, p. 123-193, 1996.

GRISI, B.M. Biomassa e atividade de microrganis- mos do solo: revisão metodológica. Revista Nordestina de Biologia, João Pessoa, v. 10, n. 1, p. 1-22, 1995.

JAHNEL, M.C.; CARDOSO, E.J.B.N.; DIAS, C.T.S. Determinação do número mais provável de microrganismos do solo pelo método de plaqueamento por gotas. Revista Brasileira de Ciência do Solo, Viço sa, v. 23, p. 553-559, 1999.

KUPERMAN, R.G.; CARREIRO, M.M. Soil heavy metal concentrations, microbial biomass and enzyme activities in a contaminated grassland ecosystem. Soil Biology and Biochemistry, Oxford, v. 29, n. 2, p. 179-190, 1997.

LEE, K.E. The functional significance of biodiversity in soils. In: WORLD CONGRESS OF SOIL SCIENCE, 15, Anais... Acapulco, International Society of Soil Science, 1994. 1994. p. 168-182.

McCUNE, B.; MEFFORD, M.J. Multivariate analysis of ecological data. Version 3.12. Gleneden Beach: MjM Software, 1997.

MELLONI, R. et al. Pó de forno de aciaria elétrica na microbiota do solo e no crescimento de soja. Pesquisa Agropecuária Brasileira, Brasília, v. 36 , n. 12 , p. 1547-1444, dez. 2001a.

. Características biológicas de solos sob mata ciliar e campo cerrado no sul de Minas Gerais. Ciência e Agrotecnologia, Lavras, v. 25, n. 1, p. 7-13, jan/fev. 2001b.

Densidade e diversidade de bactérias diazotróficas e fungos micorrízicos arbusculares em solos de mineração de bauxita. Lavras 2001c. 173f. Tese (Doutorado em Solos e Nutrição de Plantas) - Lavras, UFLA, 2001c.

MELLONI, R. et al. Impacto de resíduo de siderurgia na microbiota do solo e no crescimento de eucalipto . Revista Árvore, Viçosa, v. 24, n. 3, p. 309-315, 2000.

NANNIPIERI, P. Microbial biomass and activity measurements in soil: ecological significance. In:__KLUG, M.J.; REDDY, C.A. Current perspectives in microbial ecology. Washington: American Society for Microbiology, 1984. p. 515-521. 
PARKIN, T.B.; DORAN, J.W.; FRANCO-VIZCAÍNO, E. Field and laboratory tests of soil respiration. In: DORAN, J.W.; JONES, A.J. Methods for assessing soil quality. Madison: Soil Science Society of America, 1996. p. 231-245.

SILVESTER-BRADLEY, R. et al. Levantamento quantitativo de microrganismos solubilizadores de fosfatos na rizosfera de gramíneas e leguminosas forrageiras na Amazônia. Acta Amazônica, Manaus, v. 12, n. 15-22, mar. 1982.

STATISTICA. Statistic Analysis. Versão 5.0. 1995.
VARGAS, L.K.; SCHOLLES, D. Biomassa microbiana e produção de $\mathrm{CO}_{2}$ e N mineral de um Podzólico Vermelho-Escuro submetido a diferentes sistemas de manejo. Revista Brasileira de Ciência do Solo, Viçosa, v. 24, n. 1, p. 35-42, 2000.

WOLLUM II, A.G. Cultural methods for soil microorganisms. In: MILLER, R.H.; KEENEY, D.R. Methods of soil analysis: chemical and microbiological properties. Madison: Soil Science of American, 1982. p. 781-802. 